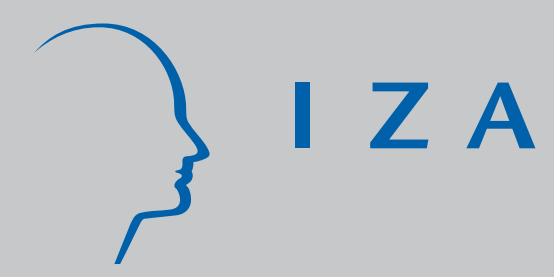

IZA DP No. 1879

Reference Dependent Preferences and the Impact of Wage Increases on J ob Satisfaction: Theory and Evidence

Christian Grund

Dirk Sliwka

December 2005 


\title{
Reference Dependent Preferences and the Impact of Wage Increases on Job Satisfaction: Theory and Evidence
}

\author{
Christian Grund \\ University of Bonn \\ and IZA Bonn \\ Dirk Sliwka \\ University of Cologne \\ and IZA Bonn
}

\section{Discussion Paper No. 1879 \\ December 2005}

\author{
IZA \\ P.O. Box 7240 \\ 53072 Bonn \\ Germany \\ Phone: +49-228-3894-0 \\ Fax: +49-228-3894-180 \\ Email: iza@iza.org
}

Any opinions expressed here are those of the author(s) and not those of the institute. Research disseminated by IZA may include views on policy, but the institute itself takes no institutional policy positions.

The Institute for the Study of Labor (IZA) in Bonn is a local and virtual international research center and a place of communication between science, politics and business. IZA is an independent nonprofit company supported by Deutsche Post World Net. The center is associated with the University of Bonn and offers a stimulating research environment through its research networks, research support, and visitors and doctoral programs. IZA engages in (i) original and internationally competitive research in all fields of labor economics, (ii) development of policy concepts, and (iii) dissemination of research results and concepts to the interested public.

IZA Discussion Papers often represent preliminary work and are circulated to encourage discussion. Citation of such a paper should account for its provisional character. A revised version may be available directly from the author. 
IZA Discussion Paper No. 1879

December 2005

\section{ABSTRACT \\ Reference Dependent Preferences and the Impact of Wage Increases on Job Satisfaction: Theory and Evidence ${ }^{*}$}

The impact of wage increases on job satisfaction is explored theoretically and empirically. To do this, we apply a utility function that rises with the absolute wage level as well as with wage increases. It is shown that when employees can influence their wages by exerting effort, myopic utility maximization directly implies increasing and concave shaped wage profiles. Furthermore, employees get unhappier over time staying on a certain job although wages increase. Using data from 19 waves of the German Socio-Economic Panel we find empirical support for both the form of the utility function and the decreasing job satisfaction patterns.

JEL Classification: $\quad$ M54, J28, J30, M12

Keywords: job satisfaction, wage increases, wage profiles, reference dependent utility, habit formation, loss aversion

Corresponding author:

Dirk Sliwka

University of Cologne

Herbert-Lewin-Str. 2

50931 Köln

Germany

Email: dirk.sliwka@uni-koeln.de 
The further we stretch

The higher the sky

It gets harder

The harder we try

The faster we run

The longer the road

The stronger we get

The bigger the load

Ezio (1995)

\section{Introduction}

Traditionally, in economic theory it is assumed that the utility respectively the well being of a person depends on absolute consumption levels in all periods of the person's lifetime. Hence, the individual objective in most models requires the maximization of the expected lifetime income, which determines directly the possible lifetime consumption path. But increased doubts are audible that this assumption is a good prediction for human behavior. In a growing number of papers the assumption is made and evidence is found that utility is not only based on the absolute amount of income, but also on the relative level with respect to a certain reference point.

The idea that relative rather than absolute utility considerations are appropriate to describe and understand human decision making dates back at least to Duesenberry (1949) and Markowitz (1952) and has found increasing empirical and theoretical support for instance in Kahneman and Tversky's Prospect Theory. ${ }^{2}$

In this paper we apply this idea to the analysis of job satisfaction ${ }^{3}$ and argue analogously that the perceived utility from a job does not only depend on the absolute wage level, but also on wage increases. The wage of the last period acts as a reference point or an aspiration level. In a first step we construct a simple model based on the assumption that an agent's utility function is strictly increasing in the absolute wage level as well as in the wage increase attained. In each period an employee can exert effort and his current wage is an increasing function of his effort level.

We then find that myopic utility maximization has some interesting implications. First of all, an employee's current effort is strictly increasing in the wage level of the previous period. The higher the previous wage, the more effort the employee has to exert to attain a higher current wage as he

\footnotetext{
${ }^{2}$ Compare for instance Kahneman and Tversky (1979) or Tversky and Kahneman (1991).

${ }^{3}$ Note, that the positive link between wages and job satisfaction is even more obvious than the correlation between wages and life satisfaction. Usually the correlation between life satisfaction and job satisfaction is very substantial.
} 
enjoys wage increases. We then show that this leads to increasing wage profiles: Although the employee's effort-wage relation remains unchanged, wages increase over time. In any period the employee tries to "beat" the standard set by the previous wage to achieve an additional wage increase.

Furthermore, as additional wage increases are increasingly costly to achieve they are declining over time. Our simple model thus predicts that wages are upward sloping and concave in an employee's tenure. Hence, we give a new explanation for the typical shape of wage profiles observed in numerous empirical studies from different countries. Previous explanations include human capital formation as stressed by Becker (1962) and Mincer (1974) or moral hazard problems which lead to deferred wage payments as proposed by Lazear $(1979,1981){ }^{4}$

We proceed by analyzing the evolution of job satisfaction over time. Most importantly we establish within our model the result that people get unhappier over time. Attaining further wage increases is more and more costly, as the reference standard set by the previous wage increases over time. Due to this effect work satisfaction decreases within our model although wages increase.

We then empirically investigate our key assumption that job satisfaction which we use as a proxy for the work related utility of an agent is indeed affected by the absolute wage level as well as the last wage increase. To do this we use data from the first 19 waves of the German Socio-Economic Panel (GSOEP) and indeed find support for the importance of reference-dependent preferences. Wage increases as well as the absolute level of wages have a significant positive impact on job satisfaction. A comparable empirical analysis has previously only been conducted by Clark (1999) with British cross section data.

But in addition we are able to establish that people indeed get unhappier over their working life. As we control for year and individual fixed effects we can confirm that this is not due to a general declining trend in overall job satisfaction but that an average individual employee's job satisfaction declines over time which confirms our theoretical prediction.

Related to some of our theoretical results is a model by Frank and Hutchens (1993) where an individual's utility depends on consumption and on the growth rate of consumption. In their model, a situation is analyzed where an employee can distribute an exogenously given fixed amount of money across all periods of his life. They show that the agent will optimally choose an

\footnotetext{
${ }^{4}$ For a survey of the arguments see for instance Hutchens (1989).
} 
increasing consumption profile. However, they verbally refer to self control problems ${ }^{5}$ by the agent to explain increasing wage profiles. In contrast, our model explicitly analyses the effort an agent exerts to attain a certain wage level and does not take life-time wages as given.

A similar strand of literature stresses the point that utility from consumption is not only affected by current consumption but also by an agent's habits. This idea is mainly modeled by applying specific parameterized utility functions that are increasing in the ratio of current consumption to a habit stock, the latter being an increasing function of past consumption. ${ }^{6}$ The particular assumptions of Prospect Theory are applied to a consumption savings problem in Bowman et al. (1999).

The paper proceeds as follows. As a starting point, in section 2 the simple theoretical model is presented. Its implications are analyzed in section 3. Section 4 examines the empirical relationship between wages and job satisfaction and empirically establishes that employees get unhappier over time. A brief conclusion discusses other possible implications.

\section{A Simple Model}

To study theoretical implications of of reference dependent preferences we introduce a simple model. We make the key assumption that in each period an employee myopically maximises his utility or job satisfaction, which depends on the current and the previous period's wage. We therefore intentionally depart from a dynamic optimisation standpoint. ${ }^{7}$ Easterlin (2001: 474) for instance argues that people do not anticipate that aspiration levels rise with increasing income and supports this claim with empirical evidence. Rabin (1998: 33-36) summarizes psychological literature and concludes: "One pattern is that we tend to underestimate how quickly and how fully we will adjust to changes, not foreseeing that our reference points will change". We will discuss this assumption of myopic maximization at the end of subsection 3.1 in more detail. ${ }^{8}$

\footnotetext{
${ }^{5}$ Lack of self control is the decisive part of the corresponding Forced Saving Hypothesis. See Clark (1999, pp. 181184) for a brief overview of the literature on this topic. See Loewenstein and Sicherman (1991) for further arguments why people may prefer increasing wage profiles and corresponding empirical evidence.

${ }^{6}$ Contributions analyzing different applications with specific utility functions are for instance the seminal article on habit formation by Ryder and Heal (1973), Abel (1990) on asset pricing, Constantinides (1990) on the equity premium puzzle or recently Carroll et al. (2000), who show that with habit formation high growth rates lead to high savings.

${ }^{7}$ For instance Bowman et al. (1999) or Frank and Hutchens (1993) examine optimal consumption paths given that individuals have reference point dependent preferences.

${ }^{8}$ A large number on contributions about loss aversion (Tversky/Kahneman 1991) indicates that status quo matters and aspiration levels change over time. Hardie et al. (1993), for instance, find that the last bought orange juice brand acts as a reference point in evaluating another one. Therefore, it seems not to be the case that aspiration levels are achieved at one certain point of time and then kept constant.
} 
We state a basic utility or job satisfaction function, which is strictly increasing in the current absolute wage $w_{t}$ and the difference between the actual wage and the last period wage denoted by $\Delta w_{t}$. Furthermore, we assume that in each period the employee can undertake activities that affect his current wage. We denote the level of wage increasing activities in period $t$ by $e_{t} \in R_{0}^{+}$. When the employee attains a wage $w$, a wage increase of $\Delta w$ and exerts an effort level $e$ in a certain period, his current utility is given by ${ }^{9}$

$$
s(w, \Delta w, e)
$$

where the wage increase in a period $t$ is given by

$$
\Delta w_{t}=w_{t}-w_{t-1}
$$

The variable $e$ may for instance encompass the effort exerted to be awarded with a wage increase or to receive a higher bonus payment. We assume that wage is an increasing and concave function of the worker's effort $e$ :

$$
w=w(e) \text { where } \frac{\partial w(e)}{\partial e}>0 \text { and } \frac{\partial^{2} w(e)}{\partial e^{2}} \leq 0
$$

There is an initial period 1 in which the employee's career starts. In this period he chooses his wage level for the first time, hence, the wage increase corresponds to the wage level. It is important to note that we assume a time invariant wage function. This implies that to achieve a certain wage level at any point in an employee's career he has to exert the same effort level. This is a natural assumption if the employee stays on his job. However, it may be less clear at first glance if he is promoted. One may think that he may be able to keep the same wage with a lower effort in the consecutive period. But it may well be argued, that the promotion brings about more responsibility and that the employee needs to exert at least as much effort as before the promotion has taken place. However, it will become clear that dropping this assumption should only strengthen our results as it will lead to steeper wage profiles.

For simplicity we assume additive separability of the utility function, in satisfaction arising from wages and wage increases on the one hand and the costs of effort on the other:

$$
s(w, \Delta w, e)=v(w, \Delta w)-c(e)
$$

\footnotetext{
${ }^{9}$ Note that such a function can of course be easily transformed to the form $u\left(w_{t}, w_{t-1}, e_{t}\right)$ that will be analyzed in the empirical part of this paper. The first derivative of the transformed function with respect to $w_{t-1}$ yields a negative sign as will be shown in the empirical investigation. However, it has turned out that the formulation given here simplifies the exposition of the theoretical results.
} 
Utility is strictly increasing in $w$ and $\Delta w$, the cost function increasing in the effort level. In addition we impose the following assumptions:

$$
\frac{\partial c(0)}{\partial e}=0, \frac{\partial^{2} c(e)}{\partial e^{2}} \geq 0, \frac{\partial^{2} v(w, \Delta w)}{\partial w^{2}}<0 \text { and } \frac{\partial^{2} v(w, \Delta w)}{\partial \Delta w^{2}}<0
$$

Hence, the marginal costs of effort are zero for an effort level of zero, the costs of wage raising activities are convex and the marginal impacts of wages and wage increases on utility are decreasing. Finally, we assume that the marginal utility of a wage increase is decreasing in the wage level

$$
\frac{\partial^{2} v(w, \Delta w)}{\partial w \partial \Delta w}<0
$$

Recall that $\Delta w$ measures the absolute and not the relative wage increase. Hence, it is natural to assume that raising a wage for someone who earns $\$ 1,000$ a month by $\$ 100$ increases his satisfaction in a stronger way than raising the wage of someone who earns $\$ 10,000$ by the same amount. $^{10}$

\section{Theoretical Implications}

\subsection{Wage Profiles}

To examine the implications of such a utility function, we inspect the optimization problem of an employee in a given period $t$ :

$$
\begin{aligned}
& \max _{e, w_{t}} v\left(w_{t}, w_{t}-w_{t-1}\right)-c\left(e_{t}\right) \\
& \text { s.t. } w_{t}=w\left(e_{t}\right)
\end{aligned}
$$

As a reference case, first consider a situation where $\Delta w_{t}$ does not enter the utility function. Then of course the optimization problem is independent from the previous wage and hence, identical in all periods. The agent would choose a constant optimal value of $e_{t}$ and thus obtain a constant wage level across all periods of the working life.

If, however, $\Delta w_{t}$ enters the utility function a different picture arises. By substituting $w_{t}=w\left(e_{t}\right)$ in the optimization problem and taking the first derivative we obtain the following first order condition:

\footnotetext{
${ }^{10}$ We will confirm this assumption empirically as an interaction term between wages and wage increases yields a negative coefficient when job satisfaction is explained.
} 


$$
\left(\frac{\partial v\left(w\left(e_{t}\right), w\left(e_{t}\right)-w_{t-1}\right)}{\partial w}+\frac{\partial v\left(w\left(e_{t}\right), w\left(e_{t}\right)-w_{t-1}\right)}{\partial \Delta w}\right) \frac{\partial w\left(e_{t}\right)}{\partial e}-\frac{\partial c\left(e_{t}\right)}{\partial e}=0
$$

As can be easily verified, the optimisation problem is strictly concave. Hence, Equation (3) defines a unique value of $e_{t}$. The optimal effort level is attained when marginal "gross" job satisfaction is equal to marginal costs of effort. This expression implicitly defines the current effort $e_{t}$ as a function of the previous wage $w_{t-1}$. To analyse the effect of the previous wage on the worker's effort choice and, hence, on his current wage, we implicitly differentiate this condition and compute $\partial e_{t} / \partial w_{t-1}$. We obtain the following result:

Lemma 1: An employee's effort and his current wage are strictly increasing in the previous wage. In the initial period a strictly positive effort and wage level is chosen.

Proof: See Appendix.

In addition to the absolute wage level, the employee enjoys wage increases above the previous wage. The higher the reference standard defined by the previous wage, the harder the employee has to work to achieve the additional satisfaction from beating this standard. From a more technical point of view, note that a higher value of $w_{t-1}$ reduces the size of the wage increase $\Delta w_{t}$ achieved with a given effort level. Due to the concavity of the utility function a higher previous wage raises the marginal impact of $\Delta w_{t}$ and thus the marginal return of effort for any value of $e_{t}$. Hence, in the optimum the employee will choose a higher effort level. As the current wage is a monotonically increasing function of $e_{t}$, it is of course also increasing in the previous wage. To see that a positive wage level is chosen in the first period, note that the reference point in the first period is a wage of zero. As the employee enjoys positive wage levels and wage increases and as we assumed that the marginal costs of effort are zero for an effort level of zero, the employee starts his career with a strictly positive wage level.

The previous result shows a positive relationship between wages in consecutive periods. It is now interesting to check whether something can be said about the slope of the earnings profile. Hence, we examine whether $w_{t}$ monotonically changes over time. Indeed we get the following result:

Proposition 1: Wages strictly increase over time.

Proof: See Appendix. 
A kind of "ratchet effect"11 exists. The higher the wage an employee attained in the previous period, the higher is the reference standard at which he evaluates current job satisfaction. Satisfaction due to a wage increase can only be achieved by exerting even more effort than in the previous period.

To understand this result, it is important to note that the marginal impact of effort on the employee's well beeing in a certain period is higher than in the preceding period if he chooses the same effort level in both periods. Therefore effort levels have to increase over time. The former is due to two effects: First, with a constant effort level, $\Delta w$ has a value of zero and due to the decreasing marginal returns its marginal impact on utility is higher in the current period if there has previously been a strictly positive wage increase. But in addition, the marginal effect of the absolute wage level on utility is also higher as absolute wage and wage increase are substitutes in generating job satisfaction. ${ }^{12}$

Hence, the current wage the employee attains will always exceed the previous wage. We have therefore shown that earnings profiles are indeed upward sloping. Finally, we examine wether our simple model yields some results on the shape of wage profiles.

Proposition 2: The wage increases $\Delta w_{t}$ decrease over time.

Proof: See Appendix.

In the previous result, we have shown that effort levels and wages rise over time. But of course, attaining further wage increases becomes more and more costly, as the marginal costs of effort increase with the effort level due to the convexity of the cost function. Therefore, the size of attained wage increases gets weaker over time. Hence, our simple theory implies that wage profiles are increasing and concave, which is an empirically well established observation.

Recall that we assume myopic maximization of job satisfaction. We have also analyzed a simple parametrized version of the model with the assumption that agents indeed dynamically optimize their intertermporal utility which is then given by the discounted sum of the instataneous utility functions depending on current wage and current job satisfaction. Numerical computations show that wage profiles increase concavely up to a certain point and then become convex up to the retirement age. Our intuition for this observation is that forward looking agents would anticipate

\footnotetext{
11 This of course should not be confounded with the ratchet effect in incentive theory.

12 As another consequence, job satisfaction declines if a wage increase fails to appear in one period for instance because of an exogenous shock. However, if the employee realizes constant wages during more than two periods he would "get used" to missing wage increases and his job satisfaction would be constant.
} 
the negative consequences of current wage increases for future job satisfaction. Hence, they would save part of their "investment" in possible wage increases up to late in their career as then the future consequences are less severe. However, we do not think that this is a good description of human behavior (and we do not observe such wage profiles in the data). We are rather convinced that people act myopically and do not take into account that attaining a high wage increase in the present makes it harder to attain high wage increases and job satisfaction levels in the future. From this point of view it seems doubtful that dynamic optimisation and reference point relatedness are compatible from a descriptive rather than normative point of view.

The most prominent explanation of increasing and concave shaped wage profiles results from human capital accumulation (see Mincer 1974). Further rationales for increasing wage profiles such as bonding and deferred compensation (Lazear 1979, 1981) or screening (Salop and Salop 1976) do not derive the concave shape of wage profiles explicitly. We do not doubt that these explanations are highly relevant. However, we have shown that employees' preferences for wage increases yield another explanation. Our result is in line with the empirical findings of Loewenstein/Sicherman (1991) that people perceive pleasure from wage increases. The respondents to their survey had to choose among different wage profiles and explain the decision thereafter. The majority of the respondents preferred increasing over decreasing and flat wage profiles in spite of lower net present values. ${ }^{13}$

\subsection{Why People Get Unhappier over Time}

We have so far analyzed the behavior of employees who maximize their current job satisfaction. As we have seen, their wages indeed increase over time. However, it seems interesting to look at the evolution of the job satisfaction of such an employee.

At first glance, the increasing wage profile might hint at an increasing job satisfaction, as the latter is an increasing function of wages. However, the second important determinant of job satisfaction in our model is the wage increase and the costs of effort to attain such wage increases. As we have seen in the last section, it gets more and more costly to achieve further wage increases. Indeed we can show that the latter two effects dominate the former:

Proposition 3: Job satisfaction decreases over time.

\section{Proof:}

\footnotetext{
${ }^{13}$ Asking employees of a medium sized German firm about their preferred wage profile for the next five years, we can confirm the reasults of Loewenstein and Sicherman. The majority of employees opts for an increasing wage profile over years, although the present value of the decreasing or constant profiles are higher.
} 
Take any two consecutive periods $t$ and $t+1$. Denote the current utility in period $t$ by $s_{t}$. From Proposition 1 we know that $w_{t+1}$ is larger than $w_{t}$ which in turn is larger than $w_{t-1}$. Furthermore, we must have that

$$
\begin{aligned}
& s_{t}=s\left(w_{t}, w_{t}-w_{t-1}, e_{t}\right) \quad \text { and } \\
& s_{t+1}=s\left(w_{t+1}, w_{t+1}-w_{t}, e_{t+1}\right) .
\end{aligned}
$$

Now suppose that the agent chooses the higher wage $w_{t+1}$ and effort level $e_{t+1}$ already in period $t$. His utility would then be given by

$$
s_{t}^{\prime}=s\left(w_{t+1}, w_{t+1}-w_{t-1}, e_{t+1}\right) \text {. }
$$

Note that $s_{t}^{\prime}$ is strictly larger than $s_{t+1}$ as wage level and thus the effort exerted are unchanged but the wage increase is larger with $s^{\prime}{ }_{t}$. But by revealed preferences we must have that $s_{t} \geq s^{\prime}{ }_{t}$. It immediately follows that

$$
S_{t}>S_{t+1},
$$

which completes the proof.

This of course yields a strong prediction: People who stay within the same environment over a certain time interval should become less and less satisfied with their job as it becomes harder to attain further wage increases. This prediction can of course be tested empirically, which we will do in the subsequent section. Additionally, we will examine whether job satisfaction indeed rises with the wage level and with wage increases, which is the main assumption of our applied job satisfaction or utility function.

\section{Empirical Evidence}

\subsection{Empirical Literature and the Data}

We assumed in the theoretical part that the utility or well being of employees does not only depend on the absolute wage level but also on wage increases, because people judge their utility with respect to a certain reference point or aspiration level, which is argued to be their wage of the prior period. ${ }^{14}$ Job satisfaction seems to be a reasonable proxy for the well being of employees with respect to their work (see Clark and Oswald 1996: 364).

There is only one prior study that analyses the impact of both wages and wage increases on job satisfaction explicitly. Clark (1999), using a cross section build from the first two waves of the

\footnotetext{
${ }^{14}$ Clark and Oswald (1996) use another possible reference point by estimating a comparison wage for each individual as a kind of aspiration level giving the average income of an employee having the same qualifications, age and so on against which the employees are supposed to compare themselves. They show that indeed higher comparison wages lead to lower job satisfaction.
} 
BHPS, finds positive effects of both variables, but astonishingly no significant effect of the absolute wage alone. Several other studies deal with job satisfaction on the basis of the GSOEP in different ways. For example, Clark et al. (1998) detect a negative effect of job satisfaction on subsequent quits. Grund (2001: 212-220) concentrates on increases of job satisfaction after job changes and Hamermesh (2001) analyses longitudinal changes in job satisfaction and points at the link between changes in income inequality and the distribution of job satisfaction. Backes-Gellner and Schmidtke (2002) examine the impact of current wages, but not the effect of wage increases, on job satisfaction for different groups of occupational status with the GSOEP.

We also use the data of the German Socio-Economic Panel (GSOEP), a large representative German survey. ${ }^{15}$ We make use of the first nineteen waves (1984 to 2002) and therefore offer the first panel study on this topic. ${ }^{16}$ Our sample is restricted to full time employees (blue collar and white collar workers), who are 20 to 60 years old and receive a gross monthly wage of at least $€ 500$ in the current and the previous year. ${ }^{17}$ For each observation we need the wage information of two consecutive years in order to analyze the effects of wage increases. Due to these restrictions we get an unbalanced panel with overall 54,385 observations. Each year there is information for 2,000 to 3,800 employees.

\subsection{Wages, Wage Increases and Job Satisfaction}

Within the GSOEP the respondents have to answer the question "How satisfied are you with your job?" using a scale from 0 (totally unhappy) to 10 (totally happy). The distribution of the answers is shown in Table 1. About half of the respondents are very satisfied with their job and state a satisfaction level of 8 or more. The average level of job satisfaction is 7.10. There is a slump in job satisfaction during the observation period. Whereas almost 60 percent of West-German employees were very satisfied with their jobs in 1985, this fraction diminishes to 49 percent in 2002. The average level of job satisfaction decreases from 7.47 to 7.08. Jürges (2003) analyzed this phenomenon in detail and shows that it can only partly be explained by cohort effects. ${ }^{18}$ The reported level of job satisfaction is on average lower in East-Germany.

\footnotetext{
${ }^{15}$ The data are provided by the German Institute for Economic Research (DIW). The questionnaire is reported at http://panel.gsoep.de/soepinfo2003/.

${ }^{16}$ See a former version of this paper (Grund and Sliwka 2003) for a particular analysis of the year 1995. Only in 1995 detailed information about the working conditions is given in the GSOEP. All qualitative results hold. Clark (1999) also examines one particular year for the UK.

${ }^{17}$ We transformed the reported wages of the year 1984 to 2001 from German Marks (DM) to Euro (€) by a division by 1.95583. All results are robust to the restriction of the data set to employees with wages of at least $€ 500$.

${ }^{18}$ Blanchflower and Oswald (2004) find a similar downward trend in the USA and Britain.
} 
We use monthly net wages as our wage variable. On average nominal wages increase from one year to the next by $4.7 \%$. About half of the employees realize yearly nominal wage increases of at least $€ 50$, but $20 \%$ have to accept wage reductions of at least $€ 50$ as well. These numbers differ only slightly across years.

Table 1: The Distribution of Job Satisfaction

\begin{tabular}{|c|c|c|c|c|c|c|}
\hline \multirow[b]{2}{*}{ Job satisfaction } & \multicolumn{3}{|c|}{ Whole sample (1985 - 2002) } & \multirow{2}{*}{$\begin{array}{c}1985 \text { (West) } \\
\text { Accumulated } \\
(\%)\end{array}$} & \multirow{2}{*}{$\begin{array}{c}2002 \text { (West) } \\
\text { Accumulated } \\
(\%)\end{array}$} & \multirow{2}{*}{$\begin{array}{c}2002 \text { (East) } \\
\text { Accumulated } \\
(\%)\end{array}$} \\
\hline & Frequency & $\begin{array}{l}\text { Percent } \\
(\%)\end{array}$ & $\begin{array}{c}\text { Accumulated } \\
(\%)\end{array}$ & & & \\
\hline (totally unhappy) & & & & & & \\
\hline 0 & 313 & 0.58 & 0.58 & 0.80 & 0.35 & 0.89 \\
\hline 1 & 289 & 0.53 & 1.11 & 1.41 & 0.83 & 1.56 \\
\hline 2 & 794 & 1.46 & 2.57 & 2.82 & 2.10 & 3.24 \\
\hline 3 & 1,644 & 3.02 & 5.59 & 5.45 & 5.21 & 6.59 \\
\hline 4 & 2,136 & 3.93 & 9.52 & 8.18 & 8.74 & 10.84 \\
\hline 5 & 5,967 & 10.97 & 20.49 & 17.86 & 18.85 & 22.23 \\
\hline 6 & 5,722 & 10.52 & 31.01 & 26.13 & 29.88 & 35.53 \\
\hline 7 & 10,434 & 19.19 & 50.20 & 41.31 & 50.92 & 59.33 \\
\hline 8 & 15,161 & 27.88 & 78.07 & 67.15 & 80.71 & 87.37 \\
\hline 9 & 7,044 & 12.95 & 91.03 & 81.48 & 94.14 & 97.09 \\
\hline $\begin{array}{l}10 \\
\text { (totally happy) }\end{array}$ & 4,881 & 8.97 & 100 & 100 & 100 & 100 \\
\hline Mean & & & 7.10 & 7.47 & 7.08 & 6.75 \\
\hline$\Sigma$ & 54,385 & 1 & & & & \\
\hline
\end{tabular}

The focus of this empirical part is to investigate whether there is an effect of wage increases on job satisfaction, which is an important assumption of our theoretical analysis. As a first indicator we examine bivariate correlation coefficient between job satisfaction and wage increases, which are defined as the difference between the current monthly net wage and the monthly net wage one year before. This correlation is significantly positive and the value $(0.05 ; p<0.01)$ is not much smaller than the correlation between job satisfaction and the absolute amount of the wages $(0.08$; $\mathrm{p}<0.01$ ). But there are other determinants of job satisfaction as well. For example, descriptive statistics indicate a strong relationship between health and job satisfaction and considerable differences across firm size categories, regions and occupational status. The average level of job satisfaction is higher in larger firms, in West Germany $(7.17)^{19}$ compared to East Germany (6.84) and for managers (7.52) compared to unskilled blue collar workers (6.66). In the following

\footnotetext{
${ }^{19}$ For East German persons there is only information from 1991 on (after re-unification in 1990). Looking only at West German employees in the years 1991 to 2002, the average level of job satisfaction (7.10) is still higher than in East Germany.
} 
analysis we use gender, age and its square, years of schooling, the marital status and year dummies as additional control variables. ${ }^{20}$

In order to analyze the effect of wage increases on job satisfaction in more detail, we make use of the panel character of the GSOEP. We estimate the effect of current wage and the wage in the previous year in addition to a set of control variables on the reported level of job satisfaction. Hence, the approach has the following form:

$$
\text { Job Satisfaction }_{t}=\alpha+\beta \cdot W A G E_{t}+\gamma \cdot W A G E_{t-1}+\delta^{\prime} X+\varepsilon,
$$

where $X$ describes the vector of the other independent variables. As can easily be seen after a simple transformation, the effect of wage increases are measured directly with this approach as (1) is equivalent to

$$
\text { Job Satisfaction }_{\mathrm{t}}=\alpha+(\beta+\gamma) \cdot W A G E_{t}-\gamma \cdot\left(W A G E_{t}-W A G E_{t-1}\right)+\delta^{\prime} X+\varepsilon .
$$

Hence, we expect a negative value for the estimated coefficient $\gamma$ in this specification.

Our dependent variable (job satisfaction) has an ordinal scale. Unfortunately there is no way to compute fixed effects ordered probit regressions. But since the partition of this variable is not too rough (11 categories), the results of a least squares regression do not differ dramatically from an ordered probit approach. Too see this, note that the results of a random effects ordered probit regression do not differ considerably from those obtained by a GLS random effects approach (see Table 2).

The results fully confirm our hypothesis. We can observe a significantly positive effect both for the wage as well as the wage increase. This result clearly contradicts traditional expected utility theory. The effect of the wage increase is in line with prior empirical British evidence of Clark (1999). However, Clark could not find a significant effect of the absolute wage alone, whereas there is a high significant effect in Germany. ${ }^{21}$

To understand this result, note the following: If we compare two workers with identical characteristics who earn the same wage say $2000 €$ with the only difference that one of them has previously earned $1500 €$ and the other one $1800 €$. Then the first worker has a significantly higher job satisfaction than the second. As we control things as education, industry, age, gender etc. there seems to be hardly another possibility than the fact that the wage of the first worker has been raised by $500 €$ and of the second by only $200 €$ that gives the first worker a higher utility. Furthermore, the second should on average even be richer as

\footnotetext{
${ }^{20}$ See Clark $(1996,1999)$ for a discussion of these control variables.

${ }^{21}$ Specifications without the wage of the previous year as an independent variable - which is not reported - lead also to highly significant effects of the wage in the current year.
} 
he has earned more money before - still he is unhappier. That cannot be explained by a neoclassical utility function.

Of course, we cannot observe the efforts exerted. But when including an unobserved effort level in the argumentation the reasoning gets even stronger: The probability is, of course, much higher that the first worker has worked harder than the second (raising my wage by $500 €$ is harder than raising it by $200 €$ ). Hence on average the disutility of effort should be higher for a worker having attained a higher wage increase. Still such a worker is happier than his colleague with the same wage but a smaller wage increase. ${ }^{22}$

Comparing the random effects model with a fixed effects approach, substantial deviations with respect to both the current monthly wage and the previous wage cannot be found. However, a Hausman test rejects the hypothesis that there are no differences of the coefficients in general. That is why we compute fixed effects regressions analyzing the effects for blue collar and white collar workers separately.

The positive effect of wage increases on job satisfaction is highly significant for white collar employees and even clearer for the subgroup of high skilled white collars. However, the effect is weaker for blue collar workers.

We can only speculate why the effect is weaker for blue collar workers. One explanation would be that not all people experience reference dependent utility and those who do are the more ambitious types (people who always try to be better off than in the status quo). Those people then might self select more often into white collar jobs where there are better career prospects. Another explanation is that the fraction of employees covered by collective wage agreements is larger among blue collar employees. But those employees have a weaker impact on their wage increases and a wage increase which is not caused by one's own achievement may be perceived as less satisfying.

The interaction term between wages and wage increases is negative and also highly significant in all but the last model specification. This observation confirms our assumption in the theoretical model that the marginal utility of a wage increase is decreasing in the absolute wage level.

\footnotetext{
${ }^{22}$ The omitted variable argument would only hold, when wage increases would be (somewhat perversely) be negatively correlated with effort levels.
} 
Table 2: Regressions on job satisfaction

\begin{tabular}{|c|c|c|c|c|c|c|c|c|c|c|c|c|}
\hline \multirow[b]{2}{*}{ Current monthly wage $(* 100)$} & \multicolumn{2}{|c|}{$\begin{array}{c}(1) \\
\text { Random Effects } \\
\text { Ordered Probit }\end{array}$} & \multicolumn{2}{|c|}{$\begin{array}{c}\text { (2) } \\
\text { Random effects }\end{array}$} & \multicolumn{2}{|c|}{$\begin{array}{c}(3) \\
\text { Fixed effects }\end{array}$} & \multicolumn{2}{|c|}{$\begin{array}{c}(4) \\
\text { Blue collars }\end{array}$} & \multicolumn{2}{|c|}{$\begin{array}{c}(5) \\
\text { White collars }\end{array}$} & \multicolumn{2}{|c|}{$\begin{array}{c}(6) \\
\text { High skilled }\end{array}$} \\
\hline & $0.036 * * *$ & (11.14) & $0.049 * * *$ & $(11.39)$ & $0.052 * * *$ & $(10.99)$ & $0.072 * * *$ & $(9.62)$ & $0.044 * * *$ & $(6.61)$ & $0.032 * * *$ & $(3.72)$ \\
\hline Monthly wage one year ago $(* 100)$ & $-0.017 * * *$ & $(5.81)$ & $-0.022 * * *$ & $(5.77)$ & $-0.022 * * *$ & $(5.31)$ & $-0.010^{*}$ & $(1.76)$ & $-0.023 * * *$ & $(3.77)$ & $-0.024 * * *$ & $(3.11)$ \\
\hline Current wage $*$ wage increase & $-0.000 * * *$ & $(4.96)$ & $-0.001 * * *$ & $(5.30)$ & $-0.001 * * *$ & $(5.61)$ & $-0.001 * * *$ & $(5.08)$ & $-0.000 * * *$ & $(3.10)$ & -0.000 & $(1.63)$ \\
\hline Female & $0.068 * * *$ & $(2.92)$ & $0.083 * *$ & $(2.55)$ & & & & & & & & \\
\hline Age & $0.012 * *$ & $(2.07)$ & $0.019 * *$ & $(2.37)$ & -0.008 & $(0.73)$ & -0.022 & $(1.43)$ & -0.021 & $(1.32)$ & $-0.064 *$ & $(1.91)$ \\
\hline Age-squared $(* 100)$ & -0.004 & $(0.56)$ & -0.009 & $(0.96)$ & $-0.027 * *$ & $(2.23)$ & -0.022 & $(1.29)$ & -0.009 & $(0.53)$ & $0.060 *$ & (1.69) \\
\hline Years of schooling & $-0.043 * * *$ & $(9.38)$ & $-0.052 * * *$ & $(8.09)$ & -0.010 & $(0.71)$ & 0.004 & $(0.20)$ & -0.021 & $(1.13)$ & -0.020 & $(0.73)$ \\
\hline East-Germany & $-0.088 * * *$ & $(3.56)$ & $-0.103 * * *$ & $(2.90)$ & $-0.380 * * *$ & $(2.78)$ & -0.384 & $(1.61)$ & -0.256 & $(1.51)$ & $-0.479 *$ & $(1.85)$ \\
\hline Satisfaction with health & $0.250 * * *$ & $(79.46)$ & $0.339 * * *$ & $(81.57)$ & $0.305 * * *$ & $(64.85)$ & $0.300 * * *$ & $(45.72)$ & $0.304 * * *$ & $(44.02)$ & $0.304 * * *$ & $(24.34)$ \\
\hline $\begin{array}{l}\quad \text { Firm size (base: } 1-19): \\
20 \text { - } 199 \text { employees } \\
200-1999 \text { employees } \\
\geq 2000 \text { employees }\end{array}$ & $\begin{array}{l}-0.028 \\
0.018 \\
0.052 * *\end{array}$ & $\begin{array}{l}(1.34) \\
(0.78) \\
(2.16)\end{array}$ & $\begin{array}{l}-0.026 \\
0.039 \\
0.090 * * *\end{array}$ & $\begin{array}{l}(0.89) \\
(1.23) \\
(2.69)\end{array}$ & $\begin{array}{l}0.027 \\
0.121 * * * \\
0.173 * * *\end{array}$ & $\begin{array}{l}(0.75) \\
(2.95) \\
(3.89)\end{array}$ & $\begin{array}{l}0.024 \\
0.084 \\
0.156 * *\end{array}$ & $\begin{array}{l}(0.47) \\
(1.40) \\
(2.32)\end{array}$ & $\begin{array}{l}0.019 \\
0.141 * * \\
0.172 * * *\end{array}$ & $\begin{array}{l}(0.34) \\
(2.35) \\
(2.74)\end{array}$ & $\begin{array}{l}0.019 \\
0.094 \\
0.145\end{array}$ & $\begin{array}{l}(0.20) \\
(0.90) \\
(1.34)\end{array}$ \\
\hline New employer & $0.150 * * *$ & $(7.00)$ & $0.181 * * *$ & $(6.22)$ & $0.203 * * *$ & $(6.44)$ & $0.136 * * *$ & $(2.83)$ & $0.284 * * *$ & $(6.62)$ & 0.083 & $(1.17)$ \\
\hline Tenure & $-0.007 * * *$ & $(6.53)$ & $-0.010 * * *$ & $(6.81)$ & $-0.022 * * *$ & $(10.34)$ & $-0.019 * * *$ & $(6.09)$ & $-0.026 * * *$ & $(8.36)$ & $-0.036^{* * *}$ & $(7.15)$ \\
\hline Marital Status Dummies (6) & \multicolumn{2}{|c|}{ Yes } & \multicolumn{2}{|c|}{ Yes } & \multicolumn{2}{|c|}{ Yes } & \multicolumn{2}{|c|}{ Yes } & \multicolumn{2}{|c|}{ Yes } & \multicolumn{2}{|c|}{ Yes } \\
\hline Occupational Status Dummies (12) & \multicolumn{2}{|c|}{ Yes } & \multicolumn{2}{|c|}{ Yes } & \multicolumn{2}{|c|}{ Yes } & \multicolumn{2}{|c|}{ Yes (5) } & \multicolumn{2}{|c|}{ Yes (7) } & \multicolumn{2}{|c|}{ Yes (2) } \\
\hline Year Dummies (19) & \multicolumn{2}{|c|}{ Yes } & \multicolumn{2}{|c|}{ Yes } & \multicolumn{2}{|c|}{ Yes } & \multicolumn{2}{|c|}{ Yes } & \multicolumn{2}{|c|}{ Yes } & \multicolumn{2}{|c|}{ Yes } \\
\hline Observations & \multicolumn{2}{|c|}{54385} & \multicolumn{2}{|c|}{54385} & \multicolumn{2}{|c|}{54385} & \multicolumn{2}{|c|}{27625} & \multicolumn{2}{|c|}{26760} & \multicolumn{2}{|c|}{8422} \\
\hline $\mathrm{R}^{2}$ within & & & \multicolumn{2}{|c|}{0.111} & 0.1 & & 0.1 & & 0.1 & & 0.1 & 21 \\
\hline $\mathrm{R}^{2}$ between & & & 0.2 & & 0.1 & & 0.1 & & 0.0 & & 0.0 & 89 \\
\hline $\mathrm{R}^{2}$ overall & & & 0.1 & & 0.1 & & 0.1 & & 0.0 & & 0.1 & 21 \\
\hline
\end{tabular}

Absolute value of $t$ statistics in parentheses

$*$ significant at $10 \% ; * *$ significant at $5 \% ; * * *$ significant at $1 \%$ 
The results of the control variables indicate that peoples' health is an important determinant for job satisfaction and men are less satisfied with their work than women. ${ }^{23}$ These results are in accordance with prior evidence of Clark (1999) and Clark and Oswald (1996). Employees in East Germany report lower levels of job satisfaction even controlling for their lower wages. Additionally, job satisfaction tends to decrease with age. The hypothesis that job satisfaction is strongly influenced by people's aspirations is confirmed by the results with regard to schooling. One should expect that aspirations increase with education as people with more years of schooling may expect higher wages (see Clark and Oswald 1996). Indeed, we find a negative effect for years of schooling on job satisfaction controlling for age and wage in the random effects regression. ${ }^{24}$.

The results are robust with regard to other specifications with only a subset of the variables and to different wage measures like gross wages and the log of wages. Using the log of wages we can measure the impact of relative wage increases on job satisfaction, which is also significantly positive. Since the following model will use absolute wage increases, we reported the compatible specification with non-transformed wages to estimate the effect of absolute rather than relative wage increases. We additionally checked that the results are robust when we use real wages (See Table 5 in the appendix).

To sum up, we find support for our hypothesis of a positive link between wage increases and job satisfaction in general and in particular for white collar workers.

\subsection{The Evolution of Job Satisfaction over time}

We finally investigate whether we can also empirically confirm that job satisfaction declines over time even though wages on average increase over time. This is the main result of our theoretical analysis in subsection 3.2. To do this we first look at the average job satisfaction of employees in two consecutive years. We split the sample in the group of persons, who stay at one particular firm (Stayer) and those who move to another firm from one year to the other (New Employer). Our considerations fit better to employees, who stay in the same environment over years. People, who change jobs and employers, are faced by a fundamentally new situation as probably, they change their jobs not without any reason.

As can be seen from Table 3, the job satisfaction of persons changing the employer increases considerably. This is because of two reasons: First, the individual is happier because he chooses a

\footnotetext{
${ }^{23}$ The gender dummy drops out for the fixed effects estimations naturally.

24 There are only very few persons in the data, who achieve a higher schooling degree while being employed. Therefore, it is not possible to find a significant effect in the fixed effects estimations.
} 
new job with certain (non-monetary) characteristics that makes him happier, but also because of a large wage increase typically coming along with that new job. ${ }^{25}$

In contrast the mean level of job satisfaction declines significantly for stayers on the basis of a simple t-test (see Table 3). ${ }^{26}$ Hence, this is a first confirmation of our theoretical results that job satisfaction of stayers decreases over time.

Table 3: Mean job satisfaction in consecutive years (Standard devations in parantheses)

\begin{tabular}{|c|c|c|c|c|}
\hline & & $J S_{t-1}$ & $J S_{t}$ & $J S_{t}-J S_{t-1}$ \\
\hline \multirow{2}{*}{ Whole Sample } & $(\mathrm{n}=50829)$ & $\begin{array}{c}7.23 \\
(1.91)\end{array}$ & $\begin{array}{c}7,09 \\
(1.95)\end{array}$ & $\begin{array}{l}-0.14 \\
(1.89)\end{array}$ \\
\hline & New employer $(n=3556)$ & $\begin{array}{c}6.55 \\
(2.34)\end{array}$ & $\begin{array}{c}7.22 \\
(2.04)\end{array}$ & $\begin{array}{l}+0.67 \\
(2.64)\end{array}$ \\
\hline \multirow{2}{*}{ White Collars } & Stayer $\quad(n=24930)$ & $\begin{array}{c}7.35 \\
(1.83)\end{array}$ & $\begin{array}{c}7.20 \\
(1.87)\end{array}$ & $\begin{array}{l}-0.15 \\
(1.79)\end{array}$ \\
\hline & New employer $(n=1830)$ & $\begin{array}{c}6.58 \\
(2.37)\end{array}$ & $\begin{array}{c}7.39 \\
(1.96)\end{array}$ & $\begin{array}{l}+0.81 \\
(2.69)\end{array}$ \\
\hline \multirow{2}{*}{ Blue Collars } & $(\mathrm{n}=25899)$ & $\begin{array}{c}7.12 \\
(1.99)\end{array}$ & $\begin{array}{c}6.98 \\
(2.01)\end{array}$ & $\begin{array}{l}-0.14 \\
(1.98)\end{array}$ \\
\hline & New employer $(n=1726)$ & $\begin{array}{c}6.52 \\
(2.30)\end{array}$ & $\begin{array}{c}7.05 \\
(2.11)\end{array}$ & $\begin{array}{l}+0.53 \\
(2.58)\end{array}$ \\
\hline
\end{tabular}

Note: $J S_{t-1}$ and $J S_{t}=$ reported level of job satisfaction in two consecutive years. GSOEP (1984-2002).

It is, however, important to note that there seems to be a general downward trend in average job satisfaction as has been found for instance for the by Blanchflower and Oswald (2004) for the USA and Great Britain and by Jürges (2003), who also uses the GSOEP, for Germany. However, given the panel structure of the GSOEP we can separately identify the effect of the general declining trend in job satisfaction and the conjectured negative effect of tenure by controlling for year effects as well as tenure in our regression. Furthermore, there are discontinuous jumps in the development of job satisfaction when a person changes jobs between different firms as argued above. To account for this we have added a dummy variable indicating whether an observation is made for the first year of an individual in a certain firm ("New Employer").

Note we already included tenure and the new employer dummy already in our key regression models reported in table 2 . Indeed the tenure variable is significantly negative for all model

\footnotetext{
${ }^{25}$ Simple regressions with our panel data explaining wage increases by tenure, the "new employer dummy", and other control variables show that changing the firm has a substantial positive impact on wage increases. This is even the case when the effect is averaged over dismissals and voluntary quits.

${ }^{26}$ Strictly speaking, this test suffers from the fact that the observations are not independent. However, analyzing each year separately, the significance holds for all but one of the 18 years.
} 
specifications. But as we also control for wages this so far only shows that people who have a higher tenure are unhappier if they earn the same wage (and wage increase) as compared to someone in a similar situation with a shorter tenure. But our theoretical result makes a stronger prediction: People should get unhappier even though they earn more money over time. To test this, we have rerun the regressions without the wage and wage increase variable. We report the results in table 4.

The effect of tenure on job satisfaction is indeed negative and highly significant in all specifications of the model. Note that year dummies are included in all specifications, such that we control for a negative time trend in overall job satisfaction in the working population. ${ }^{27}$

These results strongly support the predictions of our model: Individuals staying with the same firm get less and less satisfied over time. Note that the tenure variable measures the length of time within the same firm and not on the same job. Hence, this effect exists although many of the individuals in the sample are promoted from time to time. The explanation in the spirit of our the simple model is that it becomes more and more difficult (and thus more costly in terms of the effort exerted) to attain further promotions over the length of a career.

\footnotetext{
${ }^{27}$ The coefficients for the year dummies, which are not given in Table 4 due to space restrictions also confirm the results by Jürges (2003) that the population average of job satisfaction in Germany declined over time.
} 
Table 4: Regressions on job satisfaction excluding wage variables

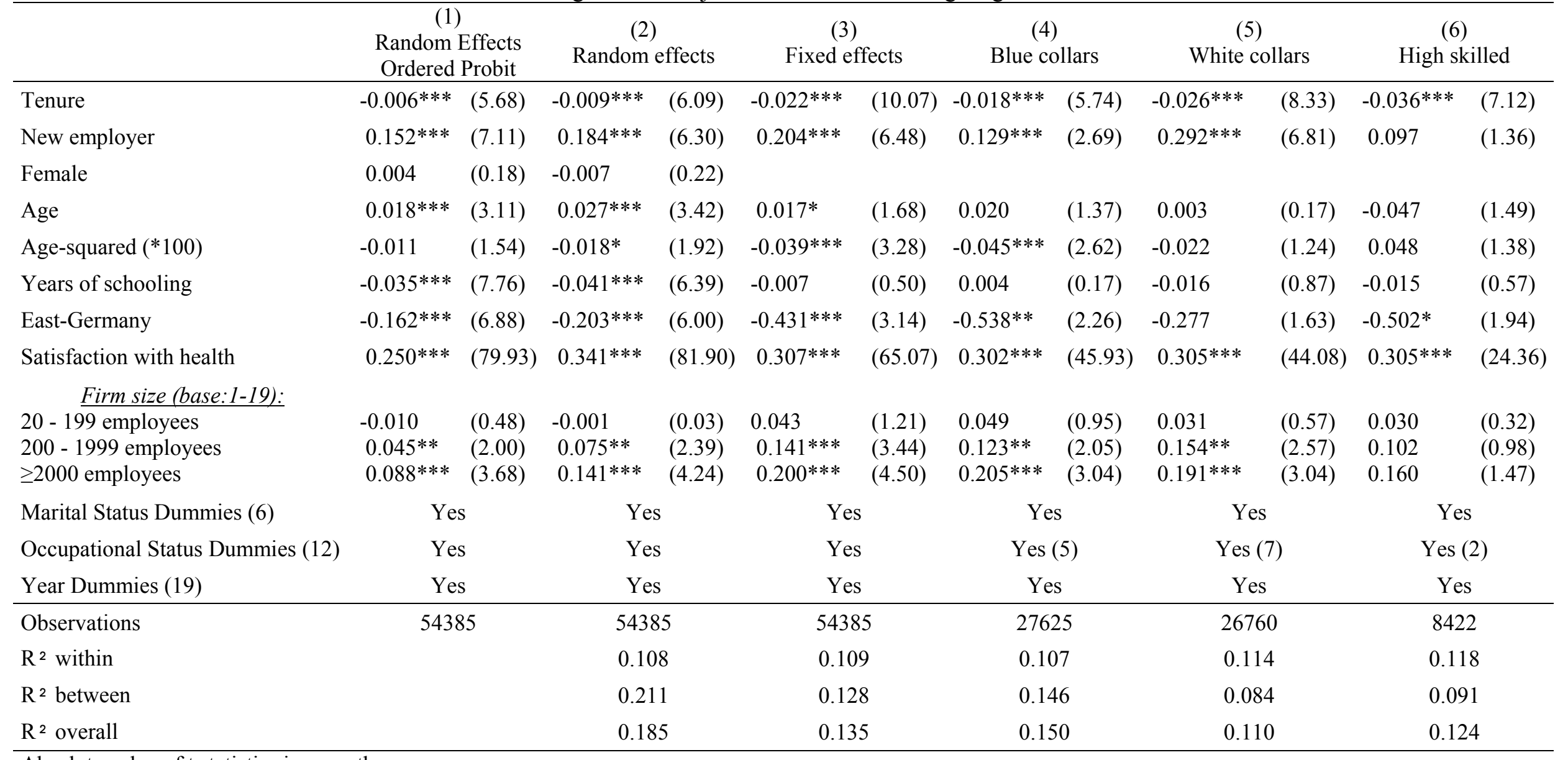

Absolute value of $t$ statistics in parentheses

$*$ significant at $10 \% ; * *$ significant at $5 \% ; * * *$ significant at $1 \%$ 


\section{Conclusion}

We have built a simple model encompassing a utility function reflecting that job satisfaction depends on wage increases as well as on the absolute wage level. Our empirical investigation has confirmed that self reported job satisfaction is indeed affected by wage increases and not only by the absolute wage level.

As we have shown, the myopic maximization of such a utility function leads to increasing and concave wage profiles. An agent works harder when his previous wage has been higher as a wage increase in itself yields additional utility.

Of course we have abstracted from many factors affecting wage profiles that are of importance in reality such as human capital formation, moral hazard problems, promotions to different jobs and so on. However, the omission of those factors strengthens our key point: Wages rise over time even in an otherwise completely stationary environment simply because employees enjoy attaining increasing wages.

However, it gets more and more difficult to attain further wage increases on the same job. Hence, as we have shown in our theoretical model and established empirically, job satisfaction decreases over time if people stay with the same firm. This yields a simple explanation for the casual observation cited in the beginning of the paper, that "the stronger we get, the bigger the load".

There are many other research questions in labor and personnel economics that might be addressed fruitfully applying reference point related utility functions. For instance, wage increase dependent well being might be another explanation for fast track effects ${ }^{28}$ in employees' careers without any necessity of information effects or ex ante heterogeneous individuals. Employees who receive high wage increases or promotions early in their career form higher reference points or aspiration levels. Hence, they work harder as compared to workers without these early successes in their occupational careers to keep up with such a standard. This should in turn lead again to quicker promotions and so on.

Furthermore, it seems interesting to look at incentive contracts in the light of such behavior. If an agent's compensation depends on his performance, this nearly always entails uncertainty as is well understood in agency theory. However, income uncertainty comes along with the possibility of income losses relative to the previous period. The kind of job satisfaction utility function suggested in this paper then leads to a double loss in the agent's well being: First, of course, as his

\footnotetext{
${ }^{28}$ Fast track effects within a firm are observable if quickly promoted employees are promoted quickly at the next level of the hierarchy as well. For theoretical explanations of and empirical evidence for fast track promotions see e.g., Rosenbaum (1979), Pucik (1991) and Baker et al. (1994). See Chiappori et al. (1999) for a corresponding "late beginner effect".
} 
absolute income level is lower. But in addition his satisfaction is further decreased due to the relative loss. This observation might help to understand why incentive contracts are much less observed in practice than suggested by standard agency theory. 


\section{Appendix}

\section{Proof of Lemma 1:}

$$
\begin{aligned}
\frac{\partial e_{t}}{\partial w_{t-1}} & =-\frac{\left(\frac{\partial^{2} v}{\partial w \partial \Delta w}(-1)+\frac{\partial^{2} v}{\partial \Delta w^{2}}(-1)\right) \frac{\partial w}{\partial e}}{\left(\frac{\partial^{2} v}{\partial w^{2}} \frac{\partial w}{\partial e}+\frac{\partial^{2} v}{\partial w \partial \Delta w} \frac{\partial w}{\partial e}+\frac{\partial v}{\partial \Delta w \partial w} \frac{\partial w}{\partial e}+\frac{\partial^{2} v}{\partial \Delta w^{2}} \frac{\partial w}{\partial e}\right) \frac{\partial w}{\partial e}+\left(\frac{\partial v}{\partial w}+\frac{\partial v}{\partial \Delta w}\right) \frac{\partial^{2} w}{\partial e^{2}}-\frac{\partial^{2} c}{\partial e^{2}}} \\
& =\frac{\left(\frac{\partial^{2} v}{\partial w \partial \Delta w}+\frac{\partial^{2} v}{\partial \Delta w^{2}}\right) \frac{\partial w}{\partial e}}{\left(\frac{\partial^{2} v}{\partial w^{2}}+\frac{2 \partial^{2} v}{\partial w \partial \Delta w}+\frac{\partial^{2} v}{\partial \Delta w^{2}}\right)\left(\frac{\partial w}{\partial e}\right)^{2}+\left(\frac{\partial v}{\partial w}+\frac{\partial v}{\partial \Delta w}\right) \frac{\partial^{2} w}{\partial e^{2}}-\frac{\partial^{2} c}{\partial e^{2}}}
\end{aligned}
$$

The sign of this expression is positive:

$$
\frac{([-]+[-])[+]}{([-]+[-]+[-])[+]+([+]+[+])[-]-[+]}=\frac{[-]}{[-]}=[+]
$$

The positive relation between the current and previous wage follows directly as $w_{t}=w\left(e_{t}\right)$ is strictly increasing in $e_{t}$.

To see that initially a positive wage level is chosen just check that the first order condition (3) cannot hold for $e_{1}=0$ as $w_{0}=0$ : The first derivative of the work satisfaction function with respect to $e_{1}$ is strictly postive at $e_{1}=0$. 


\section{Proof of Proposition 1:}

We will proceed by showing that indeed $e_{t}>e_{t-1}$ and therefore $\mathrm{w}_{t}>w_{t-1}$. As $s\left(w(e), w(e)-w_{t-1}, e\right)$ is strictly concave in $e$ a sufficient condition for this is that

$$
\left.\frac{\partial s\left(w(e), w(e)-w_{t-1}, e\right)}{\partial e}\right|_{e=e_{t-1}}>0
$$

as in that case the employee will always be able to attain a higher job satisfaction within that period by raising his effort level above the previous period's.

For the effort in the previous period $e_{t-1}$ the following first order condition must hold

$$
\left(\frac{\partial v\left(w_{t-1}, \Delta w_{t-1}\right)}{\partial w}+\frac{\partial v\left(w_{t-1}, \Delta w_{t-1}\right)}{\partial \Delta w}\right) \frac{\partial w\left(e_{t-1}\right)}{\partial e}-\frac{\partial c\left(e_{t-1}\right)}{\partial e}=0
$$

Now we examine the first derivative of work satisfaction with respect to the employee's effort in the current period $t$ :

$$
\left(\frac{\partial v\left(w(e), w(e)-w_{t-1}\right)}{\partial w}+\frac{\partial v\left(w(e), w(e)-w_{t-1}\right)}{\partial \Delta w}\right) \frac{\partial w(e)}{\partial e}-\frac{\partial c(e)}{\partial e}
$$

But if $e_{t}=e_{t-1}$ we have that $w_{t}=w_{t-1}$ and therefore $\Delta w_{t}=0$. Hence, the value of this expression is

$$
\left(\frac{\partial v\left(w\left(e_{t-1}\right), 0\right)}{\partial w}+\frac{\partial v\left(w\left(e_{t-1}\right), 0\right)}{\partial \Delta w}\right) \frac{\partial w\left(e_{t-1}\right)}{\partial e}-\frac{\partial c\left(e_{t-1}\right)}{\partial e} .
$$

As

$$
\left(\frac{\partial v\left(w\left(e_{t-1}\right), 0\right)}{\partial w}+\frac{\partial v\left(w\left(e_{t-1}\right), 0\right)}{\partial \Delta w}\right)>\left(\frac{\partial v\left(w\left(e_{t-1}\right), \Delta w_{t-1}\right)}{\partial w}+\frac{\partial v\left(w\left(e_{t-1}\right), \Delta w_{t-1}\right)}{\partial \Delta w}\right)
$$

for $\Delta w_{t-1}>0$ we must indeed have that

$$
\left.\frac{\partial s\left(w(e), w(e)-w_{t-1}, e\right)}{\partial e}\right|_{e=e_{t-1}}>0
$$

From Lemma 1 we know that the employee started his career with a positive wage level and, hence, in the first period $\Delta w>0$. As we have shown this carries over to all consecutive periods. 


\section{Proof of Proposition 2:}

We know that wages increase over time. Hence, it suffices to establish the relationship between $\Delta w_{t}=w\left(e_{t}\right)-w_{t-1}$ and $w_{t-1}$. First, note that

$$
\frac{\partial \Delta w}{\partial w_{t-1}}=\frac{\partial w}{\partial w_{t-1}}-1
$$

But,

$$
\frac{\partial w}{\partial w_{t-1}}=\frac{\partial w}{\partial e} \frac{\partial e}{\partial w_{t-1}}
$$

In Lemma 1 we have computed $\partial e / \partial w_{t-1}$. We can use this to get

$$
\begin{aligned}
& \frac{\partial w}{\partial w_{t-1}}=\frac{\partial w}{\partial e} \frac{\left(\frac{\partial^{2} v}{\partial w \partial \Delta w}+\frac{\partial^{2} v}{\partial \Delta w^{2}}\right) \frac{\partial w}{\partial e}}{\left(\frac{\partial^{2} v}{\partial w^{2}}+\frac{2 \partial^{2} v}{\partial w \partial \Delta w}+\frac{\partial^{2} v}{\partial \Delta w^{2}}\right)\left(\frac{\partial w}{\partial e}\right)^{2}+\left(\frac{\partial v}{\partial w}+\frac{\partial v}{\partial \Delta w}\right) \frac{\partial^{2} w}{\partial e^{2}}-\frac{\partial^{2} c}{\partial e^{2}}}-1 \\
& =\frac{\left(-\frac{\partial^{2} v}{\partial w^{2}}-\frac{\partial^{2} v}{\partial w \partial \Delta w}\right)\left(\frac{\partial w}{\partial e}\right)^{2}-\left(\frac{\partial v}{\partial w}+\frac{\partial v}{\partial \Delta w}\right) \frac{\partial^{2} w}{\partial e^{2}}+\frac{\partial^{2} c}{\partial e^{2}}}{\left(\frac{\partial^{2} v}{\partial w^{2}}+\frac{2 \partial^{2} v}{\partial w \partial \Delta w}+\frac{\partial^{2} v}{\partial \Delta w^{2}}\right)\left(\frac{\partial w}{\partial e}\right)^{2}+\left(\frac{\partial v}{\partial w}+\frac{\partial v}{\partial \Delta w}\right) \frac{\partial^{2} w}{\partial e^{2}}-\frac{\partial^{2} c}{\partial e^{2}}}
\end{aligned}
$$

Checking the signs, we get

$$
\frac{(-[-]-[-])[+]-([+]+[+])[-]+[+]}{([-]+[-]+[-])[+]+([+]+[+])[-]-[+]}=\frac{[+]}{[-]}=[-]
$$

Indeed, we can conclude that

$$
\frac{\partial \Delta w}{\partial w_{t-1}}<0,
$$

i.e. wage increases get smaller over time. 
Table 5: Regressions with real wages (West Germany 1985-1999)

\begin{tabular}{|c|c|c|c|c|c|c|c|c|c|c|c|c|}
\hline \multirow[b]{2}{*}{ Current monthly wage $(* 100)$} & \multicolumn{2}{|c|}{$\begin{array}{c}(1) \\
\text { Random Effects } \\
\text { Ordered Probit }\end{array}$} & \multicolumn{2}{|c|}{$\begin{array}{c}\text { (2) } \\
\text { Random effects }\end{array}$} & \multicolumn{2}{|c|}{$\begin{array}{c}(3) \\
\text { Fixed effects }\end{array}$} & \multicolumn{2}{|c|}{$\begin{array}{c}(4) \\
\text { Blue collars }\end{array}$} & \multicolumn{2}{|c|}{$\begin{array}{c}(5) \\
\text { White collars }\end{array}$} & \multicolumn{2}{|c|}{$\begin{array}{c}(6) \\
\text { High skilled }\end{array}$} \\
\hline & $0.029 * * *$ & $(8.43)$ & $0.040 * * *$ & $(8.55)$ & $0.043 * * *$ & $(8.11)$ & $0.062 * * *$ & $(7.34)$ & $0.035 * * *$ & $(4.47)$ & $0.024 * *$ & $(2.32)$ \\
\hline Monthly wage one year ago $(* 100)$ & $-0.012 * * *$ & $(4.13)$ & $-0.017 * * *$ & $(4.08)$ & $-0.016^{* * *}$ & $(3.59)$ & -0.010 & $(1.60)$ & $-0.018 * *$ & $(2.53)$ & $-0.019 * *$ & $(2.05)$ \\
\hline Current wage $*$ wage increase & $-0.000 * * *$ & $(3.98)$ & $-0.000 * * *$ & $(4.04)$ & $-0.000 * * *$ & $(4.30)$ & $-0.001 * * *$ & $(4.60)$ & $-0.000^{*}$ & $(1.71)$ & -0.000 & $(0.68)$ \\
\hline Female & $0.053 *$ & $(1.78)$ & 0.060 & $(1.47)$ & & & & & & & & \\
\hline Age & 0.005 & $(0.77)$ & 0.009 & $(0.95)$ & -0.022 & $(1.59)$ & -0.015 & $(0.78)$ & $-0.045^{* *}$ & $(2.16)$ & -0.032 & $(0.70)$ \\
\hline Age-squared $(* 100)$ & 0.005 & $(0.59)$ & 0.004 & $(0.31)$ & -0.012 & $(0.76)$ & -0.025 & $(1.13)$ & 0.014 & $(0.60)$ & 0.020 & $(0.39)$ \\
\hline Years of schooling & $-0.050 * * *$ & $(7.75)$ & $-0.063 * * *$ & $(7.20)$ & 0.002 & $(0.04)$ & -0.167 & $(1.26)$ & 0.042 & $(0.58)$ & 0.184 & $(0.96)$ \\
\hline Satisfaction with health & $0.234 * * *$ & $(62.58)$ & $0.320 * * *$ & $(63.77)$ & $0.280 * * *$ & $(49.02)$ & $0.279 * * *$ & $(36.20)$ & $0.271 * * *$ & (31.19) & $0.279 * * *$ & (17.09) \\
\hline $\begin{array}{l}\quad \text { Firm size (base: } 1-19): \\
20 \text { - } 199 \text { employees } \\
200-1999 \text { employees } \\
\geq 2000 \text { employees }\end{array}$ & -0.028 & $(0.96)$ & -0.019 & $(0.48)$ & 0.052 & $(1.00)$ & 0.043 & $(0.59)$ & 0.064 & $(0.81)$ & 0.054 & $(0.37)$ \\
\hline New employer & 0.022 & $(0.71)$ & 0.051 & $(1.20)$ & $0.166^{* * *}$ & $(2.89)$ & 0.106 & $(1.28)$ & $0.207 * *$ & $(2.42)$ & 0.140 & $(0.89)$ \\
\hline Tenure & $0.056^{*}$ & $(1.73)$ & $0.101 * *$ & $(2.28)$ & $0.215 * * *$ & $(3.50)$ & $0.188^{* *}$ & $(2.10)$ & $0.215^{* *}$ & $(2.41)$ & 0.172 & $(1.06)$ \\
\hline Marital Status Dummies (6) & \multicolumn{2}{|c|}{ Yes } & \multicolumn{2}{|c|}{ Yes } & \multicolumn{2}{|c|}{ Yes } & \multicolumn{2}{|c|}{ Yes } & \multicolumn{2}{|c|}{ Yes } & \multicolumn{2}{|c|}{ Yes } \\
\hline Occupational Status Dummies (12) & \multicolumn{2}{|c|}{ Yes } & \multicolumn{2}{|c|}{ Yes } & \multicolumn{2}{|c|}{ Yes } & \multicolumn{2}{|c|}{ Yes (5) } & \multicolumn{2}{|c|}{ Yes (7) } & \multicolumn{2}{|c|}{ Yes (2) } \\
\hline Year Dummies & \multicolumn{2}{|c|}{ Yes } & \multicolumn{2}{|c|}{ Yes } & \multicolumn{2}{|c|}{ Yes } & \multicolumn{2}{|c|}{ Yes } & \multicolumn{2}{|c|}{ Yes } & \multicolumn{2}{|c|}{ Yes } \\
\hline Observations & 35711 & & 35711 & & 35711 & & 19325 & & 16386 & & 4863 & \\
\hline $\mathrm{R}^{2}$ within & & & 0.104 & & 0.106 & & 0.106 & & 0.111 & & 0.117 & \\
\hline $\mathrm{R}^{2}$ between & & & 0.206 & & 0.080 & & 0.101 & & 0.033 & & 0.010 & \\
\hline $\mathrm{R}^{2}$ overall & & & 0.180 & & 0.097 & & 0.114 & & 0.060 & & 0.038 & \\
\hline
\end{tabular}

Absolute value of $t$ statistics in parentheses, * significant at $10 \% ; * *$ significant at $5 \% ; * * *$ significant at $1 \%$

We use prize indices from the German Federal Statistical Office which have been computed for West Germany separately until 1999. 


\section{References}

Abel, A.B. (1990): Asset Prices under Habit Formation and Catching Up with the Joneses. American Economic Review 80, 38-42.

Backes-Gellner, U.; C. Schmidtke (2002): Betriebliche Strategien gegen Fachkräftemangel. Forthcoming in: Beiträge zur Arbeitsmarkt- und Berufsforschung (BeitrAB).

Baker, G.; M. Gibbs; B. Holmstrom (1994): The Internal Economics of the Firm: Evidence from Personnel Data. Quarterly Journal of Economics 109, 881-919.

Becker, G.S. (1962): Investment in Human Capital: A Theoretical Analysis, Journal of Political Economy. 70, 9-49.

Blanchflower, D.; A.J. Oswald (2004): Well-Being Over Time in Britain and the USA, Journal of Public Economics. 88, 1359-1386.

Bowman, D.; D. Minehart; M. Rabin (1999): Loss Aversion in a Consumption-Savings Model. Journal of Economic Behavior \& Organization 39, 155-178.

Carrol, C. D.; J. Overland; D.N. Weil (2000): Saving and Growth with Habit Formation. American Economic Review 90, 341-355.

Chiappori, P.A.; B. Salanie; J. Valentin (1999): Early Starters Versus Late Beginners. Journal of Political Economy 107, 731-760.

Clark, A.E. (1996): Job Satisfaction in Britain. British Journal of Industrial Relations 34, 189-217.

Clark, A.E. (1999): Are wages habit-forming? Evidence from micro data. Journal of Economic Behavior \& Organization 39, 179-200.

Clark, A.E.; A.J. Oswald (1996): Satisfaction and Comparison Income. Journal of Public Economics 61, 359-381.

Clark, A.E.; Y. Georgellis; P. Sanfey (1998): Job Satisfaction, Wage Changes, and Quits: Evidence from Germany. Research in Labor Economics 17, 95-121.

Constantinides, G.M. (1990): Habit Formation: A Resolution of the Equity Premium Puzzle. Journal of Political Economy 98, 519-43.

Duesenberry, J.S. (1949): Income, Saving and the Theory of Consumer Behavior. Cambridge MA.

Easterlin, R.A. (2001): Income and Happiness: Towards a Unified Theory. The Economic Journal 111, 465-484.

Frank, R.H.; R.M. Hutchens (1993): Wages, Seniority, and the Demand for Rising Consumption Profiles. Journal of Economic Behavior \& Organization 21, 251-276.

Grund, C. (2001): Der zwischenbetriebliche Arbeitsplatzwechsel - Determinanten, Konsequenzen und empirische Befunde für die Bundesrepublik Deutschland. München und Mering.

Grund, C.; D. Sliwka (2003): „The Further We Stretch the Higher the Sky“ - On the Impact of Wage Increases on Job Satisfaction. Bonn Econ Discussion Papers 1/2003.

Hamermesh, D.S. (2001): The Changing Distribution of Job Satisfaction. The Journal of Human Resources 36, 1-30.

Hardie, B. G. S.; E. J. Johnson; P. S. Fader (1993): Modelling Loss Aversion and Reference Dependence Effects on Brand Choice. Marketing Science 12, 378-394.

Hutchens, R.M. (1989): Seniority, Wages and Productivity: A Turbulent Decade. Journal of Economic Perspectives 3, 49-64.

Jürges, H. (2003): Age, Cohort, and the Slump in Job Satisfaction among West German Workers. Labour 17, 489-518.

Kahneman, D.; A. Tversky (1979): Prospect theory: An Analysis of Decision Under Risk. Econometrica 47, 263-291.

Lazear, E.P. (1979): Why is there Mandatory Retirement?. Journal of Political Economy 87, 1261-84. 
Lazear, E.P. (1981): Agency, Earnings Profiles, Productivity, and Hours Restrictions. American Economic Review 71, 606-620.

Loewenstein, G.; N. Sicherman (1991): Do Workers Prefer Increasing Wage Profiles?. Journal of Labor Economics 9, 67-85.

Markowitz, H. (1952): The Utility of Wealth. Journal of Political Economy 60, 151-158.

Mincer, J. (1974): Schooling, Experience and Earnings. National Bureau of Economic Research. New York.

Pucik, V. (1991): Promotion Patterns in a Japanese Trading Company. Japanese Economic Studies 19, 37-55.

Rabin, M. (1998): Psychology and Economics. Journal of Economic Literature 36, 11-46.

Rosenbaum, J.E. (1979): Tournament Mobility: Career Patterns in a Corporation. Administrative Science Quarterly 24, 220-241.

Ryder, H.E.; G.M. Heal (1973): Optimal Growth with Intertemporally Dependent Preferences. Review of Economic Studies 40, 1-31.

Salop J.; S. Salop (1976), Self-Selection and Turnover in the Labor Market. Quarterly Journal of Economics 90, 619-627.

Tversky, A.; D. Kahneman (1991): Loss Aversion in Riskless Choice: A Reference-Dependent Model. Quarterly Journal of Economics 106, 1039-1061. 